\title{
METHODOLOGY OF TEACHING MATHEMATICS IN SCHOOL WITH APPLICATION OF APPLIED PROBLEMS AND NEW INFORMATION TECHNOLOGIES
}

\author{
Ayimbetova G.H. (Republic of Uzbekistan) Email: Ayimbetova344@ scientifictext.ru
}

\author{
Ayimbetova Gulayda Hojabergenovna - Teacher of mathematics, \\ SCHOOL № 1, XODJEYLI, REPUBLIC OF UZBEKISTAN
}

\begin{abstract}
: developed methodical recommendations to the teacher, contributing to the development of mathematical thinking in schoolchildren, in solving applied problems based on the use of the mathematical programming Mathematica. Therefore, the professional preparation of future youth should be built in such a way that in their future activity they can use software products for various purposes. To do this, the entire system of schooling should be based on the systematic application of new information technologies. Keywords: method of teaching, modeling, applied problems, programming in Mathematika.

\section{МЕТОДИКА ПРЕПОДАВАНИЯ МАТЕМАТИКИ С ПРИМЕНЕНИЕМ ПРИКЛАДНЫХ ЗАДАЧ И НОВЫХ ИНФОРМАЦИОННЫХ ТЕХНОЛОГИЙ Айымбетова Г.Х. (Республика Узбекистан)}

Айымбетова Гулайда Хожабергеновна - преподаватель математики, школа № 1, г. Ходжейли, Республика Узбекистан

\begin{abstract}
Аннотация: разработань методические рекомендации учителю, способствующие развитию математического мышления у учащчихся, при решении прикладных задач на основе использования математической среды Матһетатіса. Следовательно, профессиональную подготовку молодежи следует построить так, чтобы в своей будущей деятельности они могли применять программные продуктьл различного назначения. Для этого вся система обучения в школе должна основываться на систематическом применении новых информационных технологий.
\end{abstract}

Ключевые слова: методика преподавания, моделирование, прикладная задача, программирование в среде Mathematica.

В исследованиях по методике преподавания математики [1, 2 и др.] поставлен вопрос о необходимости явного вовлечения в школьный курс математики понятий «модель», «моделирование», доказана необходимость обучения школьников математическому моделированию, разработана общая методологическая схема обучения построению математических моделей, определено содержание основных понятий, необходимых для формирования представлений о математическом моделировании; отмечено, что отражение в школьном курсе математики элементов математического моделирования способствует решению ряда важных педагогических задач:

а) совершенствование прикладной направленности;

б) формирование элементов математической культуры и общей культуры;

в) усвоение межпредметных связей и др.;

г) использование современных информационных технологий.

В этих и других исследованиях поставлен и решён ряд важных педагогических задач, связанных с обучением моделированию и использованием его как средства учебного познания:

доказана необходимость и принципиальная возможность усвоения учащимися понятий «модель», «моделирование», «математическая модель»;

1) выделены основные элементы процесса построения математических моделей, дан анализ его операционного состава;

2) определено содержание, на котором наиболее целесообразно обучать школьников построению математических моделей (изучение новых математических понятий и решение прикладных задач);

3) установлено, что использование неэквивалентных моделей одного и того же понятия повышает эффективность его усвоения;

4) раскрыты иллюстративная и эвристические функции моделирования;

5) показано, что целенаправленное использование представлений о математическом моделировании способствует решению таких педагогических задач как формирование у школьников диалектикоматериалистического мировоззрения, воспитание творческих способностей, усиление межпредметных связей и связей обучения с практикой и т.д.;

6) ищутся конкретные методические пути обучения учащихся умению строить математические модели. 
Развитие математики как науки исторически шло по двум направлениям: внешнему и внутреннему. Внешний путь связан с необходимостью решать задачи, лежащие вне математики. В этом смысле источником развития математики явились задачи практической деятельности человека (счёт предметов, измерение площадей и объёмов, задачи экономики, техники и т.д.). Второй путь - внутренний, вытекающий из необходимости систематизации найденных математических фактов, обобщения их в теорию, развития этой теории по её внутренним законам. Именно это привело в своё время к выделению математики как науки из системы научных познаний человечества. Два названных выше пути развития называют прикладным и теоретическим.

Прикладную математику можно охарактеризовать как науку об оптимальном решении математических задач, возникающих вне математики. Соответственно, прикладная задача-это задача, поставленная вне математики и решаемая математическими средствами. Большинство авторов исследований выделяют 3 этапа в решении прикладной задачи:

1) Формализации, т.е. перевода предложенной задачи с естественного языка на язык математических терминов. Этот этап обычно называют построением математической модели задачи;

2) Решение задачи внутри модели;

3) Интерпретации полученного результата, т.е. перевода полученного результата (математического решения) на язык, на котором была сформулирована исходная задача.

Первый этап является для учащихся самым трудным. Причина этих трудностей заключается в том, что для перевода задачи с естественного языка на математический требуется иметь достаточно высокий уровень умения абстрагировать, что связано с формированием и развитием математического мышления. Отвлечение от реального объекта, его свойств и переход к математическому объекту - операция сложная, поэтому умению переводить задачу с естественного языка на математический должно быть уделено первостепенное внимание.

Мы рассматриваем математическое моделирование как важнейшее средство решения прикладных задач. Констатируется [3, с. 8], что имеющиеся в учебниках и учебных пособиях задачи по математике не способствуют в полной мере развитию познавательных интересов у учащихся, так как они представляют собой готовые математические модели и не заставляют школьников думать и искать пути оптимального решения поставленной задачи. Аналогичное мнение высказывает Л.Г. Петерсон [4, с. 31]: «Прикладная направленность курса, даже в своём внутреннем аспекте, явно недостаточна, вследствие чего учащиеся не видят связей изучаемого и обычно весьма трудного для них предмета с задачами, возникающими в их личной практике, в практике общества и любого конкретного человека. Этим и можно в определённой степени объяснить распространённое в обществе мнение о математике как науке сухой, скучной и оторванной от жизни, изучение которой в школе является не более чем неизбежным злом.

В существующей школьной практике первый и третий этапы моделирования практически полностью опускают, считая, что задачей школьного курса математики является лишь изучение математических теорий и решение задач, основным назначением которых является закрепление знаний этих теорий.

Во многих исследованиях (Р.А. Майер и др.) подчёркивается, что в имеющихся в школьных учебниках и учебных пособиях прикладных задачах ученикам приходится самим и строить модель и исследовать её, и, наконец, интерпретировать. Это требует от ученика больших усилий и затрат времени, в итоге в школе такие задачи почти не решают.

Как уже отмечалось, самым сложным для учащихся является первый этап - создание математической модели. Выработка навыков в построении математической модели должна осуществляться на протяжении всего времени изучения курсов алгебры, начал анализа и др., а не концентрироваться в каких-либо отдельных темах этих курсов. Сами задачи должны максимально использовать опыт учащихся, их живой интерес к явлениям природы, склонность к наблюдениям. В школе часто приходится решать задачи, приводящие к динамическим моделям, т.е. к моделям, которые постоянно уточняются, обновляются в зависимости от варьирования параметров моделируемого явления.

Среди существующих в настоящее время разнообразных программных продуктов для информатизации процесса обучения высшей математике наиболее подходящими являются компьютерные математические системы - интегрированные программные продукты, способные производить все виды вычислений (численных, символьных, графических) и обладающие встроенными языками программирования сверхвысокого уровня (то есть доступными для пользователя). Мы использовали для решения прикладных задач, математическую среду Mathematica, создавая индивидуальную заданию для каждого школьника. Получили результаты 95\% активности у учащихся. Применение системы Mathematica в учебном процессе школы обеспечит преемственность её применения в прикладных задач, так как школьник, приученный использовать систему Mathematica в своей учёбе, будет морально и практически готов использовать её в решении своих прикладных задач [5, с. 25].

Список литературы / References 
1. Морозов Г.М. Проблема формирования умений, связанных с применением математики: Дисс... канд.пед.наук. М.; 1978. 150 с.

2. Стукалов В.A. Использование представлений о математическом моделировании в обучении математике: Дисс... канд. пед. наук. М., 1976. 156 с.

3. Тихонов Н.Л. Задачи прикладного характера и их роль в формировании и развитии интереса к профессии у школьников при изучении математики в 6-8 классах общеобразовательной школы. М.: МПГИ им. В.И. Ленина, 1980. 62 с.

4. Петерсон Л.Г. Математическое моделирование как методологический принцип построения программы школьного курса математики // Содержание, методы и формы развивающего обучения математике в школе и вузе. Орехово-Зуево, 1995. С. 30-33.

5. Дьяконов В.П. Mathematica 4.1 / 4.2 / 5.0 в математических и научно-технических расчётах / В.П. Дьяконов. М.: СОЛОН-Пресс, 2004. 696 с. (Серия «Библиотека профессионала»). 